\title{
The role of echocardiography in the investigation of focal cerebral ischaemia
}

\author{
PETER J. BURNETT \\ F.R.A.C.P. \\ RICHARD GREENWOOD \\ M.D., M.R.C.P.
}

\author{
JOHN R. MILNE \\ M.R.C.P.
}

MARTIN R. GILES

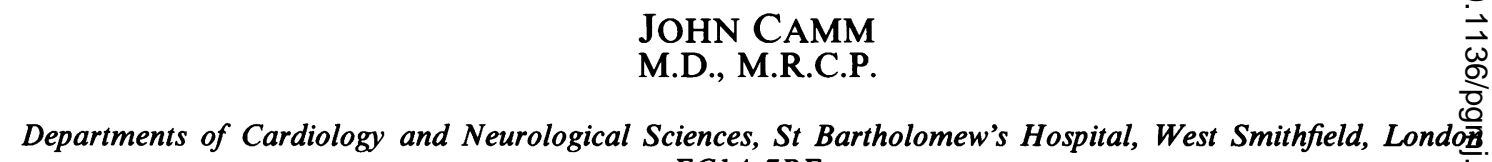

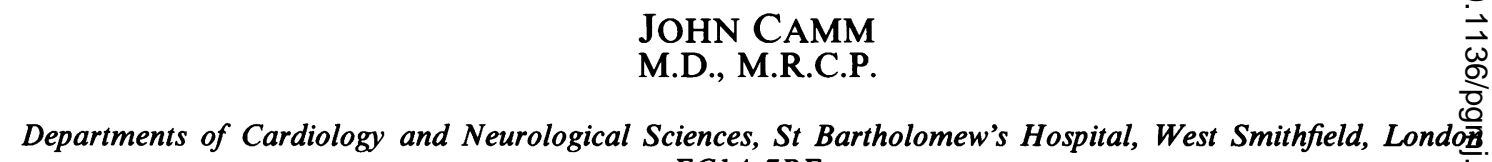
ECIA $7 B E$

\begin{abstract}
Summary
One-hundred and ten patients referred for echocardiography to exclude a cardiac source of cerebral emboli were prospectively studied. Four patients with known cardiac abnormalities, for which they were receiving inadequate anticoagulation, were excluded from the study, and 18 patients were subsequently found to have a non-embolic cause for their cerebral pathology. Twenty-eight patients with a normal clinical examination, chest X-ray and electrocardiogram, and 27 patients with hypertension alone had echocardiograms which did not reveal a cardiac source of embolus. Of the remaining group of 33 patients, six were found to have a probable cardiac source of embolus and nine had abnormalities which may be associated with cerebral emboli. Echocardiography may not be indicated in patients with a normal clinical examination, chest X-ray and electrocardiogram, and in patients with hypertension alone. However, if these patients are excluded echocardiography gives a high yeld of positive findings which may be of practical importance in the management of the patient.
\end{abstract}

KEY WORDS: hypertension, rheumatic heart disease, myxoma, myocardial diseases.

\section{Introduction}

Embolic cardiac disease may cause up to $35 \%$ of cerebral infarcts (Gautier and Morelot, 1975; Mohr $\boldsymbol{e t}$ al., 1978). Underlying cardiac pathologies which have been implicated such as rheumatic mitral valve disease (Nielson, Galea and Hossack, 1978), mitral valve prolapse (Barnett et al., 1980), bacterial endocarditis (Harrison and Hampton, 1967), left atrial myxoma (Yufe, Karpati and Carpenter, 1976), a $\overrightarrow{8}$ intracardiac thrombus due either to acute myocardial infarction (Thompson and Robinson, 1978) or cardiomyopathy (Rogers and Sherry, 1976) may not be clinically apparent and therapeutic opportunities may be missed. It is for this reason that the use 30 echocardiography has become widespread. Recentiy, Grimmer, Tindall and Hill (1982) have suggesteg that echocardiography rarely reveals clinically ugeftrl information in the absence of known cardiac disease. The purpose of this study was to determine whether routine $M$ mode and two dimensional (2D) echoc diograms were useful in the diagnosis and management of patients presenting with cerebral emboli, $\bar{g}$ r whether clinical criteria could be used to define-a subgroup in whom routine echocardiography might be indicated.

\section{Patients and methods}

One-hundred and ten consecutive patients referred for echocardiograms to exclude a cardiac source of cerebral emboli were prospectively studied. All potients had a full clinical evaluation, including electrocardiogram, chest X-ray and examination bga cardiologist prior to the echocardiogram.

$M$-mode and 2D echocardiograms were the taken using a Smith-Kline Instruments Ekosectīi (Smith-Kline Instruments Co Ltd, Welwyn Gardefils City, Herts) 1 and a $2.25 \mathrm{MHz}$ transducer with a $39^{\circ}$ scanning arc. M-mode echocardiograms were ofg tained from the standard left parasternal position, while the 2D studies included the long and short axes and apical four chamber views as previously described by Tajik et al., (1978). The echocardiograps were analysed by two experienced echocardiogrz phers. 


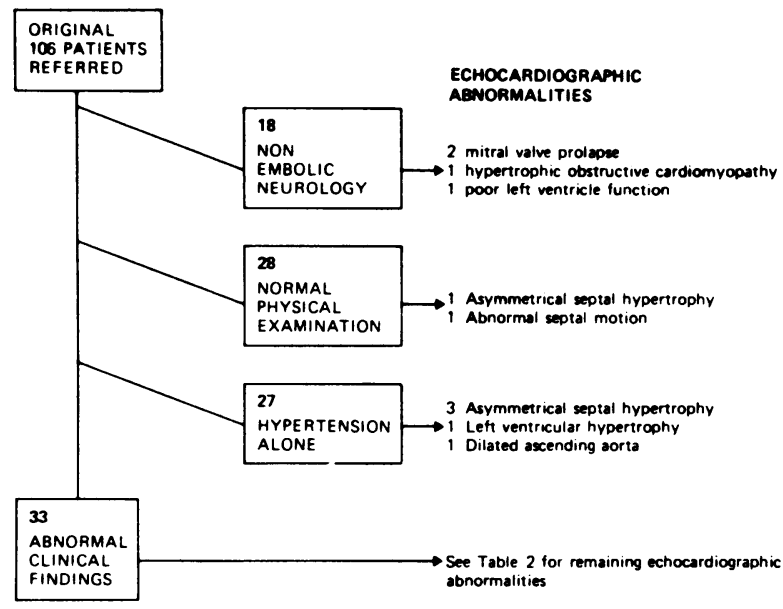

FIG. 1. Flow chart showing the echocardiographic abnormalities for the different clinical groups.

The clinical examination was thus 'blind' and was subsequently compared with the results of echocardiography. Four patients who were previously known to have a cardiac abnormality, three with prosthetic valves and one with mitral stenosis were excluded from the study, as their embolic episodes were thought to be due to inadequate anticoagulation.

\section{Results}

The study population of 106 patients (Fig. 1) consisted of 72 males and 34 females with a mean age of 58.1 years. The carotid circulation was involved in 75 patients. Fifty-three had completed infarcts and in 22 the neurological deficit lasted less than $24 \mathrm{hr}$. The posterior cerebral circulation was involved in 13 patients with nine completed strokes and four transient ischaemic attacks. After further neurological investigation, 18 patients were found to have a diagnosis which could not be related to an embolic event (for example, subdural haematoma, cortical venous thrombosis and arterio-venous malformation) and were therefore excluded from further analysis. This group included four patients with abnormal echocardiograms, two with mitral valve prolapse, one with poor left ventricular function and one with hypertrophic obstructive cardiomyopathy.

The cardiovascular examination revealed 28 normal patients with an average age of 46.1 years. Of these, only two echocardiograms were abnormal; one with asymmetrical septal hypertrophy and one with abnormal septal motion. The clinical abnormalities of the remaining 60 patients are shown in Table 1 and include 27 patients with hypertension alone. Hypertension was defined as a diastolic blood pressure of greater than $100 \mathrm{mmHg} 72 \mathrm{hr}$ after the cerebral ischaemic episode.
TABLE 1. Findings in 60 patients with clinical abnormalities

\begin{tabular}{lc}
\hline Clinical findings & Number \\
\hline Hypertension alone & 27 \\
Hypertension with other findings & 6 \\
Evidence of previous infarct & 10 \\
Atrial fibrillation & 7 \\
Mitral valve disease & 2 \\
Aortic valve disease & 3 \\
Basal systolic ejection murmur & 5 \\
Apical systolic murmur & 4 \\
Left ventricular hypertrophy (ECG) & 4 \\
Left bundle branch block & 1 \\
Pacemaker & 1 \\
Atrial septal defect & 1 \\
Loud Ist heart sound & 1 \\
\hline
\end{tabular}

Sixty-one patients had normal echocardiograms and 27 were abnormal (Table 2). Of the patients with abnormal echocardiograms, six had pathology which was likely to be related to the cerebral event. Two patients had left ventricular apical thrombi, two rheumatic mitral valve disease, one an atrial septal defect (ASD) and the sixth patient a left atrial myxoma. All these patients had clinical findings which suggested the echocardiographic diagnosîs. Both patients with left ventricular thrombus had evidence of anterior infarction on the electrocardiogram. The two patients with mitral valve disease were recognized clinically, although the diagnosis was not made prior to the neurological presentation. The 14year-old male with an ASD presented with two transient ischaemic episodes. Clinically and echocardiographically, the diagnosis was an ASD with pulmonary hypertension and paradoxical emboli. $\mathrm{He}$ subsequently underwent catheterization and was found to have total anomalous pulmonary venous drainage with a large ostium secundum defect. The 
TABLE 2. Abnormal echocardiograms

\begin{tabular}{|c|c|c|c|c|c|}
\hline \multicolumn{2}{|c|}{ Related to cerebral emboli } & \multicolumn{2}{|l|}{$\begin{array}{l}\text { Possibly related to } \\
\text { cerebral emboli }\end{array}$} & \multicolumn{2}{|c|}{$\begin{array}{l}\text { Unrelated to cerebral emboli } \\
\text { or of uncertain significance }\end{array}$} \\
\hline Apical mural thrombus & 2 & $\begin{array}{l}\text { Poor left } \\
\text { ventrical function }\end{array}$ & 5 & $\begin{array}{l}\text { Aortic valve } \\
\text { thickening }\end{array}$ & 4 \\
\hline $\begin{array}{l}\text { Rheumatic mitral } \\
\text { valve disease }\end{array}$ & 2 & $\begin{array}{l}\text { Mitral annular } \\
\text { calcification* }\end{array}$ & 3 & $\begin{array}{l}\text { Asymmetric septal } \\
\text { hypertrophy }\end{array}$ & 4 \\
\hline $\begin{array}{l}\text { TAPVD with associated } \\
\text { atrial septal defect }\end{array}$ & 1 & $\begin{array}{l}\text { Hypertrophic obstructive } \\
\text { cardiomyopathy }\end{array}$ & 1 & $\begin{array}{l}\text { Left ventricular } \\
\text { hypertrophy }\end{array}$ & 1 \\
\hline \multirow[t]{3}{*}{ Left atrial myxoma } & 1 & & & Abnormal septal motion & 1 \\
\hline & & & & Dilated ascending aorta & 1 \\
\hline & & & & Enlarged left atrium & 1 \\
\hline Total & 6 & Total & 9 & Total & 12 \\
\hline
\end{tabular}

patient with the myxoma presented with a left hemiparesis which resolved spontaneously. He had an abnormally loud first heart sound which made the physician suspicious of a cardiac lesion. All of these patients had ischaemia in the territory of the middle cerebral artery, four with completed infarcts and two with transient ischaemic episodes. Of this group, the two patients with mitral valve disease and one of the patients with left ventricular thrombus were anticoagulated. The second patient with left ventricular thrombus did not regain consciousness following the stroke and was therefore not anticoagulated. The patients with the left atrial myxoma and total anomalous pulmonary venous drainage in association with an atrial septal defect underwent cardiac surgery.

There were a further nine patients who had cardiac abnormalities which may be associated with embolic episodes. Five had poor left ventricular function, four on the basis of ischaemic heart disease and one due to long standing hypertension. Three patients had mitral annular calcification, one with associated aortic valve disease. There was one case of hypertrophic obstructive cardiomyopathy.

The abnormalities of the remaining 12 echocardiograms are shown in Table 2 . All of the abnormal echocardiographic findings in this study except the two cases of left ventricular wall apical thrombus were detected by $\mathrm{M}$-mode echocardiography.

If the patients with a normal clinical examination and hypertension alone are excluded, the remaining group of 33 patients included all those in whom the echocardiographic abnormality was thought to be related to the cerebral event.

\section{Discussion}

Echocardiography is valuable in confirming the clinical diagnosis of several cardiac lesions, which may be a source of cerebral embolus, and require specific treatment. Two recent studies by Greentann et al. (1981) and Lovett et al. (1981), in patients wott recent cerebral or retinal ischaemic episodes, conf cluded that echocardiography is not routinely ind cated in these patients because of the low yield of positive findings. Our study has confirmed this conclusion, and also failed to show the high incidence of mitral valve prolapse in young patients wit cerebral ischaemia previously reported by Barnett $e_{3}$ al. (1980).

In our study there were three cases of mitrat annular calcification. De Bono and Warlow (1979 found mitral annular calcification in eight of 15 里 patients presenting with retinal or cerebral ischaemiz compared with none from matched controls. The clinical relevance of this finding remains uncertai and as it affects elderly patients it is difficult to recommend anticoagulation, although a clinical triat of antiplatelet therapy may be indicated.

Although patients with coronary artery disease may have similar pathology in their cerebral vessels? the presence of left ventricular thrombus in a patient with previous myocardial infarction and recents cerebral ischaemia makes the probability of an embolus high. In the present study, left ventricular thrombus was found in two of six patients with anterior myocardial infarction. In the four patient with inferior myocardial infarction no echocardio graphic evidence of thrombus was found. Although these numbers are small, they are in keeping with the 
work of Asinger et al. (1981), who found echocardiographic evidence of thrombus in 12 of 35 patients with acute anterior myocardial infarction, whereas in 35 patients with acute inferior myocardial infarction no thrombi were seen. Although the presence of left ventricular thrombus infrequently results in systemic emboli (Cabin and Roberts, 1980) anticoagulation is indicated when associated with cerebral ischaemia.

Whether the case of hypertrophic obstructive cardiomyopathy should have been included in the group of cardiac disorders which may cause cerebral ischaemia is debatable, particularly as an arrhythmia was not documented. Although Hardarson et al. (1973) reported an association between hypertrophic obstructive cardiomyopathy, atrial fibrillation and cerebral embolism, cerebral embolic episodes have recently been shown to be a rare complication by McKenna et al. (1981). The relevance of the cardiac lesions in three patients with clinical and echocardiographic evidence of aortic valve disease, and five patients with basal systolic ejection murmurs, two of whom had aortic valve thickening on echocardiography, is also uncertain. It was felt that these clinical and echocardiographic findings were probably not related to the cerebral ischaemic episode, because although the associations of retinal arterial occlusion (Wilson, Warlow and Ross Russell, 1979) and spontaneous calcific embolization (Holley et al., 1963) with aortic valve disease are well recognised, focal cerebral ischaemia due to aortic valve disease in the absence of endocarditis appears to be uncommon.

As in previous studies, we found a relatively high incidence of atrial fibrillation in these patients. This again emphasizes the frequency of cerebral emboli in patients with atrial fibrillation from any cause (Wolf et al., 1978; Hinton et al., 1977) especially when associated with other cardiac disease.

The results of this study confirm that echocardiography is not indicated in patients presenting with cerebral ischaemia who have normal clinical examination, chest X-ray and electrocardiogram, or in patients with hypertension alone. In this study, two dimensional echocardiography had little or no advantage over M-mode echocardiography except in the presence of a large anteroseptal infarct when left ventricular mural thrombus was suspected clinically. However, in patients with abnormal cardiac findings there is a high incidence of echocardiographic abnormalities. In five of the 33 patients in this subgroup, management was altered as a result of the echocardiographic findings. In particular, two-dimensional echocardiography is indicated following stroke in patients with previous anterior wall myocardial infarction to detect mural thrombus.

\section{References}

Asinger, R.W., Mikell, F.L., Elsperger, J. \& Hodges, M. (1981) Incidence of left ventricular thrombosis after acute transmural myocardial infarction. New England Journal of Medicine, 305, 297.

Barnett, H.J.M., Boughner, D.R., TAYlor, D.W., CoOper. P.E., KosTUK, W.J. \& NiCHOL, P.M. (1980) Further evidence relating mitral valve-prolapse to cerebral ischaemic events. New England Journal of Medicine, 302, 139.

CABIN, H.S. \& RoBERTS, W.C. (1980) True left ventricular aneurysm and healed myocardial infarct: rarity of systemic emboli despite frequency of intra-aneurysmal thrombi. Circulation. 62 (Abstr.) (Suppl. 3), 37.

BONO, D.P. DE \& WARLOW, C.P. (1979) Mitral-annulus calcification and cerebral ischaemia. Lancet, ii, 383.

Gautier, J.C.\& Morelor, D. (1975) Infarctus cerebraux: étude de leur prevention. Nouvelle Presse Medicale. 4, 2575

Greenlani), P., Knopman, D.S., Mikell, F.L., Asinger, R.W., ANDERSON, D.C. \& GOOD, D.C. (1981) Echocardiography in diagnostic assessment of stroke. Annals of Internal Medicine, 95 51.

Grimmer. S.F.M., Tindall. H. \& Hill, J.D. (1982) Diagnostic contribution of echocardiography. Lancet, $\mathrm{i}, 440$.

hardarson, T., Calzada, C.S. de la, Curiel, R. \& Goodwin. J.F. (1973) Prognosis and mortality of hypertrophic obstructive cardiomyopathy. Lancet, ii, 1462.

HARRison, M.J.G. \& HAMPTON, J.R. (1967) Neurological presentation of bacterial endocarditis. British Medical Journal, 2, 148.

hinton, R.C., Kistler, J.P., Fallon, J.T., Freidlich, A.L. \& FISHER, C.M. (1977) Influence of etiology of atrial fibrillation on incidence of systemic embolism. American Journal of Cardiologv, 40, 509.

Holley. K.E.. Bahin, R.C., MCGoOn, D.C. \& Mankin, H.T. (1963) Spontaneous calcific embolisation associated with calcific aortic stenosis. Circulation, 27, 197

Lovett, J.L., URTON, A., SANdok, B.A., Giuliani, E.R.\& Nasser. F.N. (1981) Two-dimensional echocardiography in patients with focal cerebral ischaemia. Annals of Internal Medicine, 95, 1.

McKenna. W., Deanfield, J., Faruqui, A., England, D., OakLEY. C. \& GoodwIN, J. (1981) Prognosis in hypertrophic cardiomyopathy: role of age and clinical, electrocardiographic and haemodynamic features. American Journal of Cardiologl, 47, 532.

Mohr, J.P.. CaPlan, L.R.. Melski, J.W.. Goldstein, R.J.. DuN(AN. G.W.. Kistler, J.P., Pessin, M.S. \& Bleich, H.L. (1978) The Harvard cooperative stroke registry: a prospective registry. Neurology (Minneapolis), 28, 754.

NiEl.SON, G.H., Galea, E.G. \& Hossack, K.F. (1978) Thromboembolic complication of mitral valve disease. Australian and New Zealand Journal of Medicine, 8, 457.

Rogers. P.H. \& ShERRY, S. (1976) Current status of antithrombotic therapy in cardiovascular disease. Progress in Cardiovascular Diseases, 19, 235

TAJik, A.J.. Seward, J.B., Hagler, D.J., Mair, D.D. \& LiE. J.T. (1978) Two-dimensional real time ultrasonic imaging of the heart and great vessels. Mayo Clinic Proceedings, 53, 271.

ThOMPSON, P.L. \& RoBinson, J.S. (1978) Stroke after acute myocardial infarction: relation to infarct size. British Medical Journal, 2, 457.

Wilson, L.A., Warlow, C.P. \& Ross Russell, R.W. (1979) Cardiovascular disease in patients with retinal arterial occlusion. Lancet, i, 292.

Wolf, P.A., DAwber, T.R., Thomas, H.E. \& Kannell, W.B. (1978) Epidemiologic assessment of chronic atrial fibrillation and the risk of stroke: the Framingham study. Neurology (Minneapolis). 28, 973

YuFe, R., KaRPati, S. \& CARPENTER, S. (1976) Cardiac myxoma: a diagnostic challenge for the neurologist. Neurology (Minneapolis). 26. 1060 .

(Accepted 7 June 1983) 